\title{
The human component of sustainability: a study for assessing "human performances" of energy efficient construction blocks
}

\author{
Erminia Attaianese ${ }^{\mathrm{a}, *}$, Gabriella Duca ${ }^{\mathrm{a}}$ \\ a Department DICATA / LEAS Laboratory, University of Naples Federico II, Via Tarsia 31, 80135, Naples, Italy
}

\begin{abstract}
This paper presents an applied research aimed at understanding the relevance and the applicability of human related criteria in sustainability assessment of construction materials. Under a theoretical perspective, human factors consideration is strongly encouraged by building sustainability assessment methods, but the practice demonstrates that current models for building sustainability assessment neglect ergonomic issues, especially those ones concerning the construction phase. The study starts from the observation that new construction techniques for high energy efficient external walls are characterized by elements generally heavier and bigger than traditional materials. In this case, high sustainability performances connected with energy saving could be reached only consuming high, and then not very much sustainable, human efforts during setting-up operations. The paper illustrates a practical approach for encompassing human factors in sustainability assessment of four block types for energy efficient external walls. Research steps, from block selections to bricklaying task analysis, human factors indicators and metrics formulation, data gathering and final assessment are going to be presented. Finally, open issues and further possible generalizations from the particular case study will be discussed.
\end{abstract}

Keywords: Bricklaying, task analysis, human factors indicators, metrics, construction techniques.

\section{Introduction: human factors in buildings and construction sustainability}

Human and social aspects are today commonly considered as key factors in sustainable policies and practices. Despite that, in building and construction field, given the great environmental impact of construction industry, sustainability is generally addressed to the assessment of natural resources consumption in the building lifecycle.

Under a theoretical perspective several approaches to sustainability in construction state the relevance of the consideration of human component in the built environment, but few practices based on this concept have been implemented for all phases of the construction process [1]

In the majority of cases, human factors are taken into account with reference to health, wellbeing and safety of building occupants. In this view, attention is paid mainly to healthiness of HVAC systems or ma- terials. Sometimes a mention is given to "ergonomics" of furniture, which is no clearer elicited. Anyway, for what concerns the construction phase of the building process, all currently used sustainability assessment methods for buildings (such as LEED, BREEAM, ITACA, etc.) do not mention human factors issues nor provide some related indicators [2].

Thus a first thought about the proposed topic is that assessment of building sustainability should consider resource consumption in the building lifecycle in a broader meaning, including aspects closer to human related issues [3].

On the other hand, it can be observed that traditional construction materials and techniques have reached over the time a sort of standardization, based on human capabilities and body dimensions. With this regard, it can be observed that traditional bricks have almost the same dimensions and weight all over the world, given their correspondence to grasping and strength ability of human upper limbs.

\footnotetext{
* Corresponding author. E-mail: erminia.attaianese@unina.it
} 
Today, many new construction products and systems are purposely designed to assure very high energy-efficiency performances, but the focus on energetic performances brings to a sort of disregard towards other characteristics, relevant for safety and quality of laying phase, that were implicitly considered in traditional construction techniques. This is clear in the case of external wall materials, for which it can be observed that the need to increase thermal insulation brings to blocks generally heavier and bigger than traditional ones, with a possible consequent worsening of working conditions for bricklayers.

The present paper discusses an applied research aimed at understanding ergonomic performances of energy efficient bricklaying systems, based on a purposed protocol for the comparison of four type of products covering the most popular product typologies.

\section{The compared assessment of human factors performances of energy-efficient bricklaying systems}

\subsection{Methodological approach}

The study started from the observation that traditional construction materials, and especially blocks, have reached an optimization in weight and dimensions as consequence of human hands dimensions and strength abilities. This sort of informal standardization (that is the implicit fitting of construction materials to human characteristics) may be questioned by the use of innovative materials conceived to enhance energy performances in buildings. Compared with traditional bricklaying elements, high energyefficient blocks have generally consistencies, shapes, dimensions or weights rather different from traditional wall-brick systems. These differences let suppose that changes in bricklayers workload have come up [4], and a deeper understanding of workers resources needed for job completion is worthy to be investigated. Here, a study is presented based on the comparison of 4 types of external wall blocks offering comparable high acoustic and thermal performances; selected blocks have been assessed in order to understand the type and quantity of human effort needed for their setting-up. In developing the assessment protocol, following data have been taken into account in order to provide an exhaustive consideration of human factors in bricklaying step of building lifecycle [5], [6], [7]:
- description of blocks technical characteristics in terms of: dimensions and weight, shape and aids for grasping, cutting, laying

- task analysis, detailing bricklayers actions, number and type of movements, physical demand for each type of construction material

- context of use of the block system, including tools \& complementary materials (e.g mortar) description and injury risks for laying each type of block.

\subsection{Construction techniques to be compared}

Market analysis showed two main typologies of materials for high energy performances external walls: load bearing masonry and curtain masonry. Moreover, this kind of masonry can be prefilled with insulating materials or need to be assembled joining more layers each of one with its specific structural, insulation, finishing function. A further classification is given by the presence or not of slots facilitating surface continuity and providing guidance in bricklaying execution.

After this initial survey, four blocks were chosen for the compared assessment:

a. load bearing, shuttering blocks, prefilled with insulating material, with slots

b. load bearing blocks, pre-layered with insulating expanded-clay, with slots

c. curtain clay blocks, prefilled with perlite, with slots

d. curtain masonry, made up by inner clay blocks, insulating filling and external brickfaced layer.

All considered systems provide comparable thermal transmittance and soundproof performances.

Technical characteristics of selected blocks were gathered in a table showing:

- block width length and height

- block weight

- thermal and soundproof performances

- $\quad$ quantity of plaster needed (if any)

- $\quad$ quantity of mortar needed (if any)

- $\quad$ quantity and type of insulating material needed (if any)

- $\quad$ quantity of iron and concrete needed (if any)

- $\quad$ aids for grasping, cutting, laying

- $\cos t$

except for data describing features of referred to a single block, all data were expressed per square meters. 


\subsection{Task analysis of blocks laying}

Task analysis was conducted in two steps. First one was a hierarchical task analysis of the four construction techniques represented with flowcharts, where construction steps were broken down into elementary tasks (see Figure 1). The second step was a detailed task analysis where each elementary task was explained describing the bricklayers detailed actions, number and type of movements, physical demand, tools \& complementary materials used and their characteristics, efforts and injury risk related to tools and materials needed for laying each type of block.

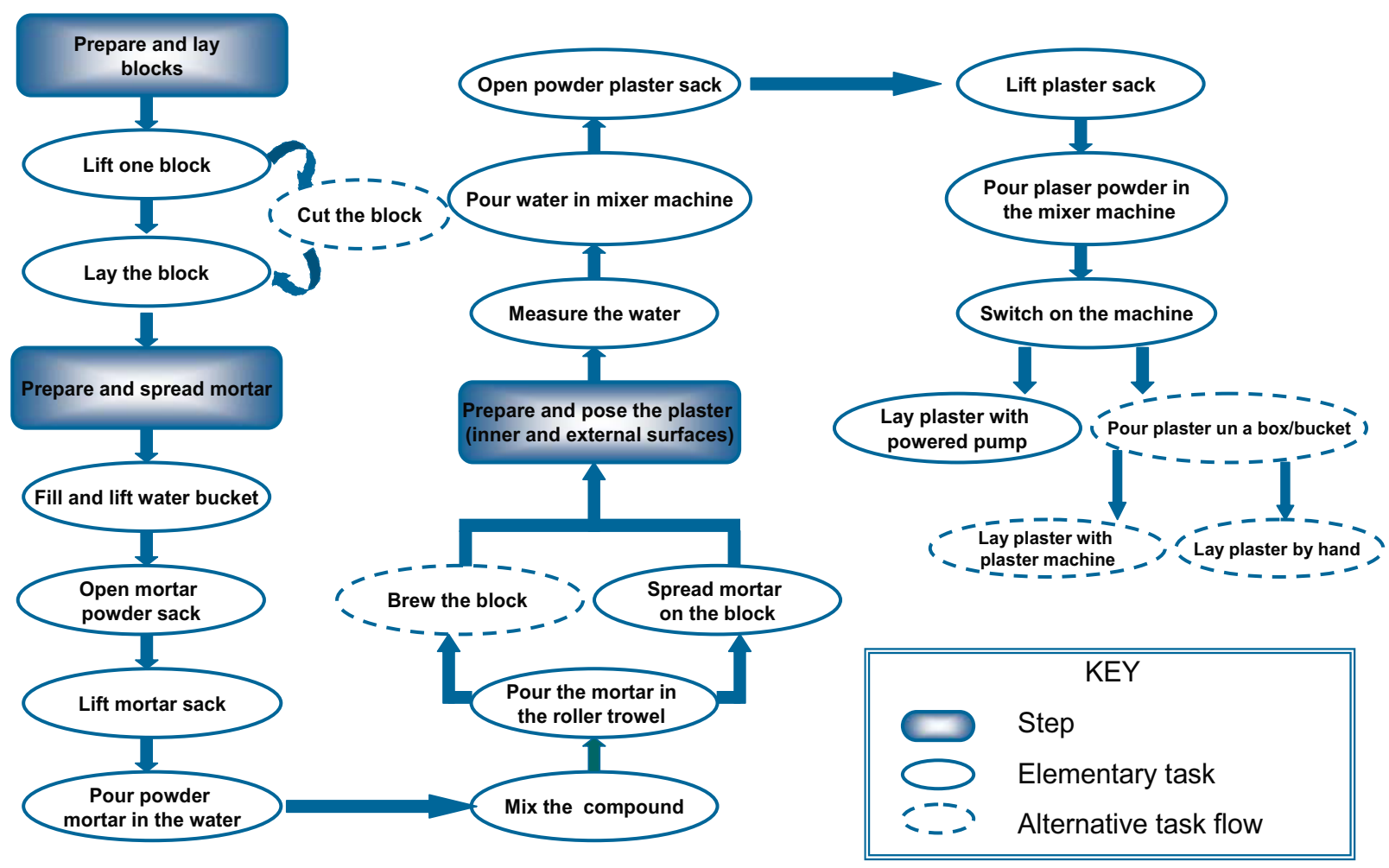

Figure 1: Flowchart representing hierarchical task analysis of block system "c"

\subsection{Human related indicators for sustainability assessment}

After having completed technical description of blocks and bricklaying job, a set of human performance indicators was defined, addressing following criteria [8]:

- $\quad$ objects grasp/grip

- $\quad$ trunk movements with reference to midrange

- upper-limbs movements with reference to midrange
- $\quad$ strength exertion with reference to power-zone

- upper-limb vibration absorption

- produced wastes

- presence of hurting parts

- $\quad$ use of hurting equipment

- $\quad$ easiness of bricklaying job

Each assessment criterion was elicited in performance indicator/s with appropriate metrics, as described in Table 1. It has to be noticed that the ongoing bricklaying job represents a changing working context, since vertical and horizontal reference distances for task accomplishment varies according the 
number of block courses layered. For that reason, assessment was conducted referring to the job of building a wall 3 meter long and 3 meters high, and deviations form reference metrics were calculated for each block course.

Table 1

Table of indicators and metrics for human factors assessment of energy-efficient block.

\begin{tabular}{|c|c|c|c|}
\hline \multicolumn{2}{|c|}{$\begin{array}{c}\text { ASSESSMENT CRI- HF PERFORMANCE INDICA- } \\
\text { TERIA } \\
\text { TOR }\end{array}$} & \multicolumn{2}{|c|}{ METRICS } \\
\hline $\begin{array}{l}\text { Grip and grasps of } \\
\text { handled objects } \\
\text { (block and tools) }\end{array}$ & $\begin{array}{l}\text { - Grip type (hook, palm, } \\
\text { pinch etc.) } \\
\text { - Grip dimension } \\
\text { - Grip shape and position } \\
\text { - Symmetry of handling }\end{array}$ & $\begin{array}{l}\text { Number of objects to be } \\
\text { used without adequate } \\
\text { grip (Deviation of grip } \\
\text { dimension from } 95^{\circ} \text { or } \\
5^{\circ} \text { percentile of the ref- } \\
\text { erence body measure - } \\
\text { the applicable value ac- } \\
\text { cording the case) }\end{array}$ & $\begin{array}{l}\text { Number of items grasped not } \\
\text { symmetrically per } 9 \text { square me- } \\
\text { ters of wall }\end{array}$ \\
\hline $\begin{array}{l}\text { Trunk flex- } \\
\text { ion/extension }\end{array}$ & - Extent of the movement & $\begin{array}{l}\text { Deviation from mid- } \\
\text { range (number of ex- } \\
\text { tensions types) }\end{array}$ & $\begin{array}{l}\text { Number of flexions/extensions } \\
\text { per } 9 \text { square meters of wall }\end{array}$ \\
\hline $\begin{array}{l}\text { Upper limbs flex- } \\
\text { ion/extension }\end{array}$ & - Extent of the movement & $\begin{array}{l}\text { Deviation from mid- } \\
\text { range (number of ex- } \\
\text { tensions types) }\end{array}$ & $\begin{array}{l}\text { Number of flexions/extensions } \\
\text { per } 9 \text { square meters of wall }\end{array}$ \\
\hline Manual lifting & - Lifted weight & $\begin{array}{l}\text { Deviation from power } \\
\text { zone (number of devia- } \\
\text { tion types, e.g. lateral, } \\
\text { vertical...) }\end{array}$ & $\begin{array}{l}\text { Number of lifting per } 9 \text { square } \\
\text { meters of wall }\end{array}$ \\
\hline $\begin{array}{l}\text { Vibrations from } \\
\text { manual of powered } \\
\text { tools }\end{array}$ & - Vibration intensity (m/s2) & $\begin{array}{l}\text { Number of vibration } \\
\text { sources }\end{array}$ & $\begin{array}{l}\text { Time of vibration exposure per } \\
9 \text { square meters of wall }\end{array}$ \\
\hline Produced waste & $\begin{array}{l}\text { - Spalls } \\
\text { - Powder } \\
\text { - Spurts }\end{array}$ & \multicolumn{2}{|c|}{$\begin{array}{l}\text { Number of source of potential dangerousness wastes (in- } \\
\text { cluding all used materials per technique) }\end{array}$} \\
\hline $\begin{array}{l}\text { Hurting parts in } \\
\text { blocks and other } \\
\text { needed materials }\end{array}$ & $\begin{array}{l}\text { - Cutting parts } \\
\text { - Scabrous parts } \\
\text { - Fragile or instable consis- } \\
\text { tence }\end{array}$ & \multicolumn{2}{|c|}{$\begin{array}{l}\text { Number potentially injuring parts per block (that is number } \\
\text { of ways of injuries occurrence) }\end{array}$} \\
\hline $\begin{array}{l}\text { Use of hurting } \\
\text { equipment }\end{array}$ & $\begin{array}{l}\text { - Cutting tools } \\
\text { - Percussion tools }\end{array}$ & $\begin{array}{l}\text { Number of potentially } \\
\text { dangerous tools used }\end{array}$ & $\begin{array}{l}\text { Number of times of dangerous } \\
\text { tools are used }\end{array}$ \\
\hline Easy of setting up & - Steps for setting up & \multicolumn{2}{|c|}{ Number of steps needed for setting up } \\
\hline
\end{tabular}

As shown in Table 1, a first attempt to cover a rather broad range of HF issues in assessing bricklaying works was conducted quantifying many, even if heterogeneous, facts representing not optimal ergonomic working conditions. Gaps between optimal ergonomic conditions and actual working condition resulting from each specific construction block were from each specific construction block were counted, taking into account -when possible- either the number of discrepancies types either the number of times when they occur.

Therefore, once metrics were defined, measures have been gathered and rough data have been repre- 
sented in charts in order to give evidence of differences in human factors performances provided by the four block types. Charts in Figure 2 illustrate with some examples the variability of human factors per- formances levels offered by energy efficient construction blocks under investigation.
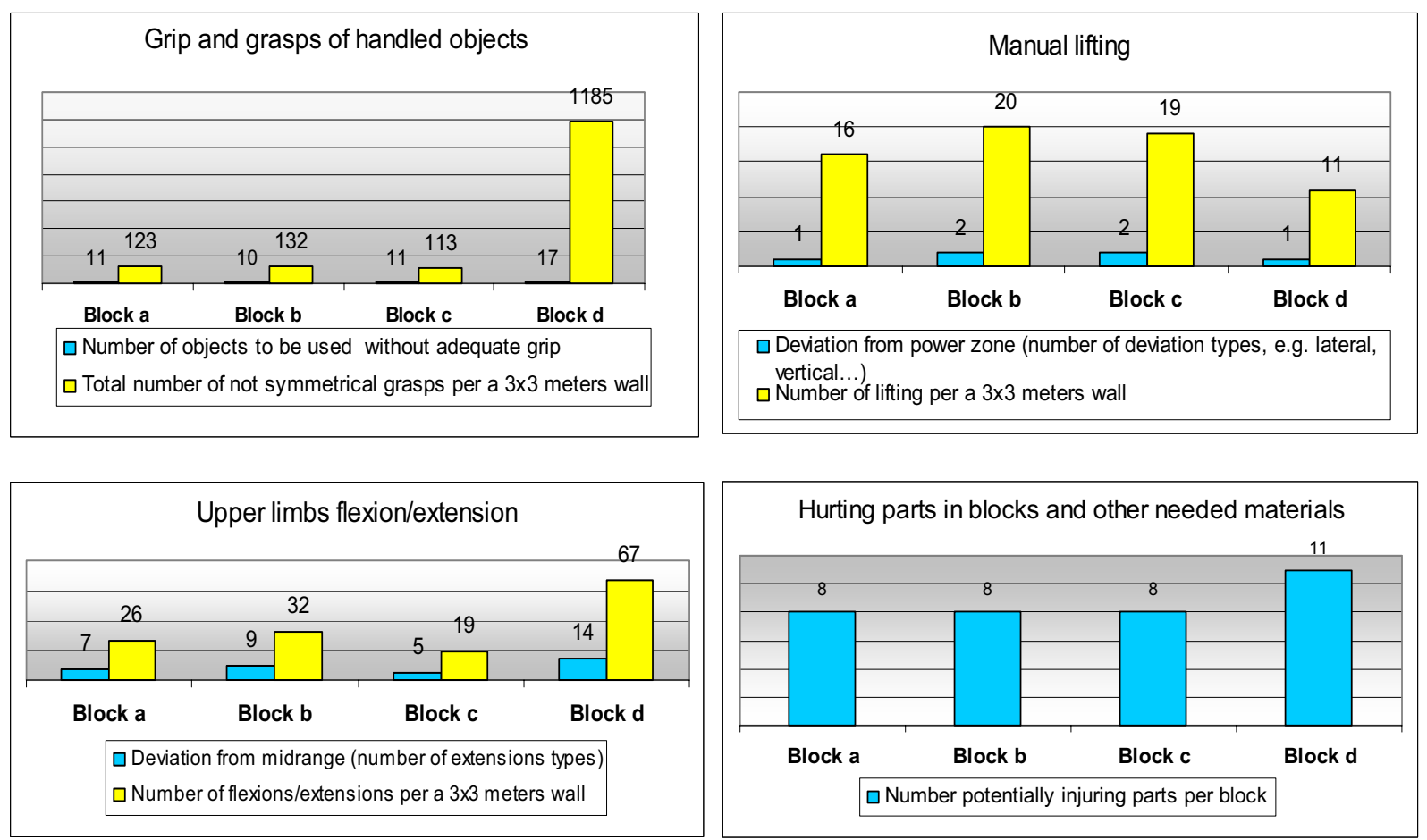

Figure 2: Sample charts of analytic comparisons for of energy efficient construction blocks under investigation.

\section{Results}

A synthetic comparison of human performances provided by the four block types investigated was done summarizing all ergonomic critical situations observed during the previous phase of analytic data gathering. Despite more accurate data, able to give account of the actual weight of each performance indicator, are not yet available, research first findings demonstrate that techniques with similar energy performances can offer very different performances under workers perspective, highlighting the fact that technical innovations in worksites could determine working conditions worst than traditional construction techniques or other comparable competitors.

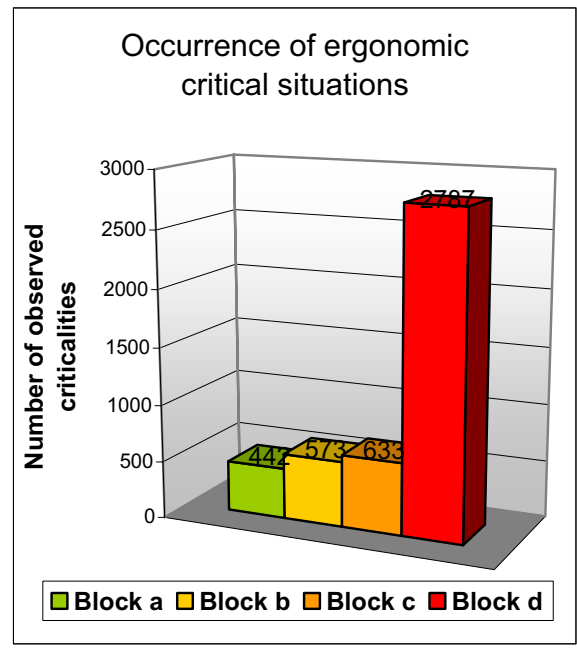

Figure 3: Synthetic assessment of human performances of analysed energy efficient construction blocks. 
More in detail, two techniques show similarly acceptable value of human factor performances (namely block types "b" and "c"), whilst one offers slightly better HF performances (block type "a"). Finally, the forth one offers very worst ergonomic working conditions, at least in comparison with the other three considered blocks (see Figure 3).

\section{Discussion}

Results have verified the initial hypothesis of the need of more accurate consideration of human factors in concept and delivery of new materials for construction.

Further refinements in the proposed assessment methodology would be fostered, mainly addressing a scoring system for quantitative data gathered for each HF aspect considered. In fact, such improvement would allow to better estimate the weight of each achieved measurement in the whole human factors performance calculation, pondering the actual relevance they have in bricklaying operation comfort and safety.

The presented study demonstrates that a more comprehensive application of sustainability principles is viable in the construction field. In fact, the followed approach has experimented in the practice that current sustainability methods applied in building industry can be enriched including human related aspects among sustainability indicators, supporting a quantitative comparison of alternative products, accordingly with the overall sustainability approach.

Finally, it can also be considered that designers choices can significantly affect workers ergonomic conditions, since comparable or equivalent products under the barely technical point of view can produce very dissimilar working conditions. This seems to be a relevant and more general critical point in architectural design process management, opening the door for further investigations in the field of "workers driven" architectural design and corporate social responsibility for construction materials manufacturers."

\footnotetext{
- Authors would like to thank Miss Veronica Lamberti for her accurate job of data gathering.

Editorial note for Italian readership: paragraphs from 1 to 2.3 can be attributed to E.A, whilst paragraphs from 2.4 to 4 can be attributed to G.D.
}

\section{References}

[1] J.Vedder and E. Carey, A multi-level systems approach for the development of tools, equipment and work processes for the construction industry. Applied Ergonomics 36 (2005), 471480

[2] A. Hedge, The Sprouting of "Green" Ergonomics. HFES Bulletin 51 (12) (2008), 1-3

[3] T. Lützkendorf, and D. Lorenz, Integrating sustainability into property risk assessments for market transformation. Building Research \& Information, 35 (2007) 644 - 661

[4] P. Entzel, J. Albers, and L. Welch, Best practices for preventing musculoskeletal disorders in masonry: Stakeholder perspectives. Applied Ergonomics 38 (2007) 557-566

[5] P. D. Bust, A. G. F. Gibb, and R. A. Haslam,. Manual handling of highway kerbs-focus group findings. Applied Ergonomics 36 (2005) 417-425

[6] J. A. Hess, L. Kincl, T. Amasay and P. Wolfe, Ergonomic evaluation of masons laying concrete masonry units and autoclaved aerated concrete. Applied Ergonomics 41 (2010) 477483

[7] S. Salem, A. Genaidy, J. Albers, R. Shell, T. Sobeih and M. M. Rinder, Use and acceptability of reduced-weight Portland cement bags in masonry construction: An observational pilot study, Human Factors and Ergonomics in Manufacturing, 18 (3), (2008) 253-269

[8] E. Attaianese, G. Duca, N. Coppola, G. De Margheriti, R. Pascale and V. Troisi, Assessment of ergonomic quality of hand-held materials and packaging in constructions. Proceedings TG59 \& W112 - Special Track 18th CIB World Building Congress, CIB Publication 359 (2010) 32-43 